Utah State University

DigitalCommons@USU

Green Canyon Environmental Research Area, Logan Utah

Quinney Natural Resources Research Library, S.J. and Jessie E.

1988

\title{
A Seasonal Comparison of Metabolic and Water Loss Rates of Three Species of Grasshoppers
}

Lynn J. Forlow

James A. MacMahon

Follow this and additional works at: https://digitalcommons.usu.edu/grcanyon

Part of the Ecology and Evolutionary Biology Commons, Entomology Commons, and the Plant

Sciences Commons

\section{Recommended Citation}

Forlow, L. and MacMahon, J. (1988). Seasonal comparison of metabolic and water loss rates of three species of grasshoppers. Comparative Biochemistry and Physiology - Part A: Molecular \& Integrative Physiology, 89(1): 51-60.

This Article is brought to you for free and open access by the Quinney Natural Resources Research Library, S.J. and Jessie E. at DigitalCommons@USU. It has been accepted for inclusion in Green Canyon Environmental Research Area, Logan Utah by an authorized administrator of DigitalCommons@USU. For more information, please contact digitalcommons@usu.edu.

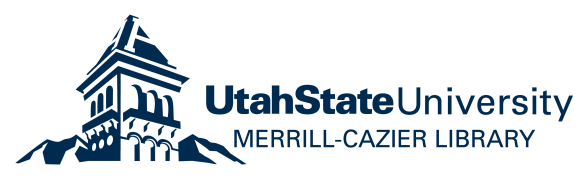




\title{
A SEASONAL COMPARISON OF METABOLIC AND WATER LOSS RATES OF THREE SPECIES OF GRASSHOPPERS
}

\author{
LynN J. Forlow and James A. MacMahon* \\ Department of Biology and Ecology Center, Utah State University, Logan, UT 84322-5305, USA
}

(Received 22 April 1987)

\begin{abstract}
Seasonal differences in metabolic and water loss rates were examined in three related species of grasshoppers collected from shrub-steppe communities in Utah: Arphia conspersa, A. pseudonietana and 2 cohorts of Trimerotropis pallidipennis.

2. No significant differences $(P=0.05)$ in metabolic rates were observed between seasons (early vs late), between genera (Arphia vs Trimerotropis) nor among species.

3. Early season (spring) grasshoppers had a higher (but non-significant) mean water loss rate $(\bar{X} \pm S D$ in $\left.\mathrm{mg} \cdot \mathrm{g}^{-1} \cdot \mathrm{hr}^{-1}\right)(4.81 \pm 1.53)$ than late season (summer) grasshoppers $(4.43 \pm 1.43)$.

4. Among species, early season $A$. conspersa had a significantly higher water loss rate $(5.22 \pm 1.76)$ under similar conditions than late season A. pseudonietana $(3.67 \pm 1.22)$, but early season $T$. pallidipennis had a significantly lower water loss rate $(4.40 \pm 1.17)$ than the late season generation $(5.32 \pm 1.12)$.

5 . Because of variables that were not or could not be controlled, the relationship between these physiological traits and season was difficult to address.
\end{abstract}

\section{INTRODUCTION}

Insects experience difficulty in regulating body water because of their high surface area to volume ratios. The ability to conserve body water, whether through behavioral or physiological adaptations, influences the abundance, distribution, and activities of insects (Vollmer and MacMahon, 1974). The problem of water regulation is magnified in arid habitats because of high vapor pressure deficits.

Experiments have demonstrated that insects active during times of potential water stress have lower water loss rates than those active when water stress is low. Ahearn and Hadley (1969) found that under similar conditions, a midsummer species of tenebrionid beetle, Cryptoglossa verrucosa, lost water less rapidly than a fall species, Eleodes armata. Edney (1971) showed that desert tenebrionids active during the day lost water less rapidly than those active at night. In addition, under the same temperature and desiccating regimen, a mesic-adapted species had higher water losses than any of the desert forms. In a study of desert cockroaches, Cohen and Cohen (1981) reported higher water loss rates for Arenivaga apacha, a species that forages in moist rodent burrows, than for $A$. investigata, which forages through dry sand.

Several studies have associated insect metabolism (which is closely linked with water regulation) with diurnal and seasonal activity patterns. Cohen and Cohen (1981) concluded that Arenivaga investigata was better adapted to stressful desert conditions than was $A$. apacha; the former had an increase in $Q_{10}$ from 1.2 at a $20-30^{\circ} \mathrm{C}$ range to 2.6 at a $30-40^{\circ} \mathrm{C}$ range. The workers suggested the insects were approaching their optimal temperature. In contrast, the

*To whom correspondence may be addressed.
$Q_{10}$ of $A$. apacha decreased from 1.8 to 1.2 for the same temperature ranges indicating the animals were reaching lethal temperatures.

Studies that relate metabolism and water balance to insect activity patterns and habitat choice are common. Little work has been done on how these physiological traits affect the distribution and activities of one prominent desert dwelling group of insects, the grasshoppers.

Grasshoppers provide an excellent opportunity for a study in water conservation because they are widely distributed, easily collected and well-known taxonomically. Additionally, many aspects of their general physiology have been studied extensively (Clarke, 1957; Weis-Fogh, 1967; Loveridge, 1968a, b; Shaw and Stobbart, 1972; Mispagel, 1978). Despite this potential, work on the ecophysiology of grasshoppers has been restricted either to single species (Duke and Crossley, 1975; Mispagel, 1978; Hadley and Massion, 1985) or to species that share the same habitat at the same time (Anderson et al., 1979; Gillis and Possai, 1983).

Few studies have examined the response of grasshoppers with and without water stress. Abushama (1970) reported that under controlled conditions, Anacridium melanorhodon, a mesic species, had a greater water loss rate than Poecilocerus hieroglyphicus, a species of more xeric habitats. Massion (1983) and Chappell (1983a) compared different species along altitudinal gradients. Although the high and low elevations were mesic and xeric habitats, respectively, the workers emphasized the affects of seasonal length on metabolism and water balance. Massion (1983) hypothesized that the higher rate of water loss in the high altitude species had 2 major causes: (1) the insects lost more water through their respiratory systems because of their greater metabolic rates, and (2) the threat of desiccation was less 
because of the availability of free water from succulent vegetation.

An ideal situation for making ecophysiological comparisons would be to use groups of closelyrelated grasshoppers that co-occur during periods of the year that differ in moisture characteristics. Some members of the genera Trimerotropis and Arphia meet these critcria. Arphia conspersa and the first cohort of Trimerotropis pallidipennis are present in the spring and early summer. Arphia pseudonietana and the second cohort of Trimerotropis pallidipennis can be found in the late summer.

In shrub-steppe communities of northern Utah, spring temperatures are low and soil moisture is high due to winter precipitation (Caldwell and Fernandez, 1975; Fogel, 1981). As summer progresses soil water potential decreases and unless the soil is recharged by rain, plant water potentials also decrease (Harris and Campbell, 1981; Sala et al., 1981).

Since grasshoppers obtain water with their food, plant water dynamics may affect the water regulation mechanisms in the insects. Early season grasshoppers may have higher water loss rates and yet be less water stressed due to the availability of free water from succulent food plants. In contrast, late season grasshoppers may have lower water loss rates because of some acquired response to that potentially water stressing time of late summer.

This study was undertaken to compare oxygen consumption and water loss rates of 4 groups of grasshoppers (2 species of Arphia and 2 cohorts of Trimerotropis pallidipennis) at 2 seasons, spring (early season) and summer (late season). Two predictions were tested: under similar laboratory conditions, (1) early season grasshoppers would have metabolic rates lower than late season grasshoppers and (2) early season grasshoppers would have water loss rates higher than late season grasshoppers. Any differences found, even after laboratory acclimation, may indicate genetic rather than environmental history differences. If season is the most important variable, then between species, interseasonal differences will be greater than differences within a season.

\section{MATERIALS AND METHODS}

Collection and pre-experimental maintenance

Males of $A$. conspersa, A. pseudonietana and $T$. pallidipennis were collected from five locations in Utah during the spring and summer of 1985 . Collection sites and the species collected at each site are summarized in Table 1.
The grasshoppers collected were acclimated in wire mesh cages for a minimum of one week at $22^{\circ} \mathrm{C}$. Various grasses, fresh lettuce, and bran were provided ad libitum and unlimited water was available in a plastic petri dish containing saturated cotton.

\section{Metabolic rates}

Methods of oxygen consumption determination were modified from Mispagel (1981) and Massion (1983). Individual grasshoppers were placed in standard one-arm, $25 \mathrm{ml}$ flasks. A paper wick saturated with $10 \% \mathrm{KOH}$, a carbon dioxide absorbant, was inserted in the side well of each flask. The flasks containing the grasshoppers and the $\mathrm{KOH}$ were then immersed in a water bath at $22^{\circ} \mathrm{C}$ and allowed to equilibrate for $1 \mathrm{hr}$. After equilibration, oxygen consumption was measured at $10 \mathrm{~min}$ intervals for $30 \mathrm{~min}$. Following the $22^{\circ} \mathrm{C}$ run, the water bath temperature was increased to $32^{\circ} \mathrm{C}$ and the insects were allowed to equilibrate at this temperature before the new test was begun.

After the completion of each $32^{\circ} \mathrm{C}$ run, live weights of the grasshoppers were measured to $0.1 \mathrm{mg}$ with a Mettler analytical balance. Any fecal pellets present were weighed with the grasshoppers to correct for weight lost due to defecation. Fecal pellets were present because the grasshoppers were not starved prior to the experiments. Clarke (1957), Keister and Buck (1964) and Riddle (1978) reported that starvation depresses metabolic rate in insects and other arthropods.

The term metabolic rate (synonymous with oxygen consumption rate and respiration) is defined as microliters of oxygen consumed per gram body mass per hour $\left(\mu \mathrm{l} \cdot \mathrm{g}^{-1} \cdot \mathrm{hr}^{-1}\right)$. Metabolic rate was expressed as a function of live weight.

Only males were used for the respiration experiments since females have highly variable metabolic rates, attributed to gonadal development (Guerra and Cochran, 1970; Loveridge and Bursell, 1975).

Data for individuals that failed to survive the entire procedure were discarded. The sample size for each population was as follows: $A$. conspersa, $22 ; A$. pseudonietana, 40 ; early season $T$. pallidipennis, 36; late season $T$. pallidipennis, 40. For each species, a $Q_{10}$ value was calculated for the $22-32^{\circ} \mathrm{C}$ range. Individuals that survived the respiration runs were later used for desiccation trials.

\section{Water loss rates}

Water loss was determined using a modification of a technique described by Edney (1971). Individual grasshoppers (treatments and controls) were placed in small plastic cages of known weight. The center of one side of the cage had a hole covered with nylon mesh for air circulation. The cages and enclosed grasshoppers were weighed and then placed either in desiccation chambers containing indicator Drierite ${ }^{\mathbb{B}}$ (treatments) or chambers without Drierite ${ }^{\mathbb{B}}$ (controls). The Drierite ${ }^{(8)}$ maintained the relative humidity near $0 \%$. Test insects did not have access to food and water

Table 1. Species, collection dates and localities of grasshoppers captured in Utah in 1985

\begin{tabular}{|c|c|c|}
\hline Species & $\begin{array}{c}\text { Date } \\
\text { collected }\end{array}$ & Location \\
\hline A. conspersa & $\begin{array}{l}20 \text { May } \\
8 \text { June }\end{array}$ & $\begin{array}{l}\text { Blacksmith Fork Canyon, Cache County } \\
41^{\circ} 38^{\prime} \mathrm{N} 1111^{\circ} 48^{\prime} \mathrm{W} \text {, elevation } 1500 \mathrm{~m} \\
\text { Pine Valley, Washington County } \\
37^{\circ} 25^{\prime} \mathrm{N} 113^{\circ} 34^{\prime} \mathrm{W} \text {, elevation } 1750 \mathrm{~m}\end{array}$ \\
\hline A. pseudonietana & 19 July & $\begin{array}{l}\text { Green Canyon, Cache County } \\
41^{\circ} 47^{\prime} \mathrm{N} 111^{\circ} 48^{\prime} \mathrm{W} \text {, elevation } 1500 \mathrm{~m}\end{array}$ \\
\hline $\begin{array}{l}\text { Early season } \\
\text { T. pallidipennis }\end{array}$ & 8 June & $\begin{array}{l}\text { Pine Valley, Washington County } \\
37^{\circ} 25^{\prime} \mathrm{N} 113^{\circ} 34^{\prime} \mathrm{W} \text {, elevation } 1750 \mathrm{~m}\end{array}$ \\
\hline $\begin{array}{l}\text { Late season } \\
\text { T. pallidipennis }\end{array}$ & 3 August & $\begin{array}{l}\text { Skull Valley, Tooele County } \\
40^{\circ} 45^{\prime} \mathrm{N} 112^{\circ} 50^{\prime} \mathrm{W} \text {, elevation } 1320 \mathrm{~m}\end{array}$ \\
\hline
\end{tabular}


during the trials. Control animals were provided water in eye droppers containing soaked cotton wicks. The droppers were inserted into holes punched in one wall of the cage and were easily removed prior to each weighing session. The initial weights of each grasshopper and cage were measured at the beginning of the trial, which started at 0500 MDT. The desiccators were then placed in an incubator set at $22^{\circ} \mathrm{C}$. The cages were removed from the desiccators and weighed every $3 \mathrm{hr}$. Desiccation trials continued for $42 \mathrm{hr}$. Since the insects were not pre-desiccated to remove water adhering to the cuticle, weight loss at the first 3-hr period was recorded but not included in the analysis. No data were collected at the 21 st hr $(0200 \mathrm{MDT})$ of desiccation.

During the $42 \mathrm{hr}$ trial, any individuals found lying on their sides and unable to right themselves were considered dead. Both dead and live insects (plus any fecal pellets present) were weighed and dried to a constant weight in an oven set at $66^{\circ} \mathrm{C}$.

Mean water loss rates $\left(\mathrm{mg} \mathrm{H}_{2} \mathrm{O} \cdot \mathrm{g}^{-1} \cdot \mathrm{hr}^{-1}\right)$ and cumulative water losses $\left(\mathrm{mg} \mathrm{H}_{2} \mathrm{O} \cdot \mathrm{g}^{-1}\right)$ were calculated for each experimental group.

Each treatment was replicated 4 times with a minimum of 10 individuals in each replicate. There was one replicate of 5 individuals for each control.

Fifteen dried specimens per grasshopper group were used to estimate the surface area to volume ratios. The body was divided into geometrical shapes whose areas could be calculated from appropriate dimensions of the grasshopper (Vollmer and MacMahon, 1974). The head was considered a prolate spheroid; the body was considered a cylinder; the legs were ignored because they are often held against the body at rest, thus not functionally increasing surface area.

\section{Statistical procedures}

Analysis of variance (ANOVA) was used to compare oxygen consumption and water loss rates between early and late season grasshoppers and between genera. Protected LSD tests were used after ANOVA (Steele and Torrie, 1980) for interspecific comparisons.

Regression lines were fitted to all respiration and water loss data. A linear regression model was used for the respiration data. Preliminary statistical analysis on the water loss data showed that the variances were not constant. Therefore, the data were transformed and fitted to a quadratic regression model of the form $\sqrt{ } Y=a+b X+c X^{2}$. The equality of slopes and intercepts for all pair-wise respiration and desiccation comparisons were determined using formulae described by Graybill (1976). Statistical significance was set at $P=0.05$.

\section{RESULTS}

Respiration and water loss rates were compared between seasons (early vs late), between genera (Arphia vs Trimerotropis) and among species. Four pair-wise comparisons were made among species with reference to season and genera (Fig. 1). Although there were 3 species of grasshoppers, for the sake of clarity, 4 "species" were considered here because of the 4 interspecific comparisons. Measurements presented in parentheses are means plus or minus the standard deviations $(\bar{X} \pm \mathrm{SD})$.

\section{Body weights and body water contents}

Mean weights among the species (measured after the respiration trials) ranged from $241.2 \pm 46.9 \mathrm{mg}$ for late season Trimerotropis pallidipennis to $381.4 \pm$ $60.1 \mathrm{mg}$ for Arphia conspersa. Intermediate to these were $A$. pseudonietana $(327.9 \pm 37.6 \mathrm{mg})$ and early season $T$. pallidipennis $(319.9 \pm 45.6 \mathrm{mg})$.

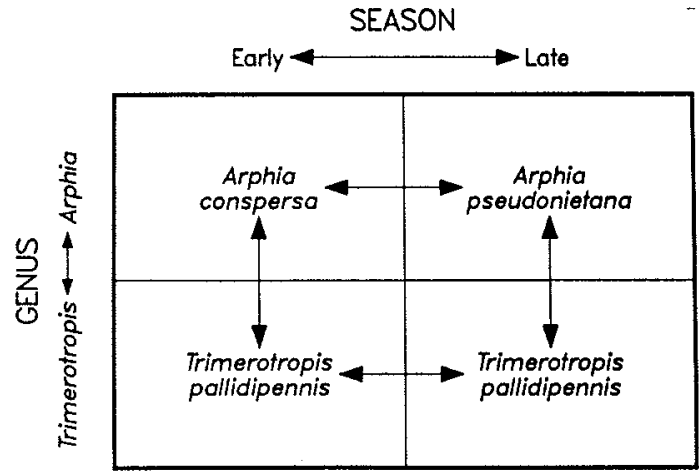

Fig. 1. Representation of the 6 comparisons made among 3 species of grasshoppers (2 species of Arphia and 2 cohorts of Trimerotropis pallidipennis). Each comparison was made with reference to various metabolic rate and water loss measurements.

By the time of initial weighing for the desiccation trials, the live weights of the groups had decreased for all but late season $T$. pallidipennis, but weight distribution was similar to the respiration weights. The pre-desiccation mean weights for late season grasshoppers were significantly less $(280.3 \pm 41.3 \mathrm{mg})$ than early season grasshoppers $(310.0 \pm 59.8 \mathrm{mg})$ $(F=9.31, \mathrm{df}=1,90)$.

Body water contents were calculated using the wet and dry weights obtained during the desiccation trials. There was no relationship between body size and percent body water among the 4 "species". When the species were considered with reference to season, the late season grasshoppers had a significantly greater water reserve $(74.2 \pm 3.6 \%)$ than the early season grasshoppers $(69.8 \pm 2.2 \%)(F=24.1, \mathrm{df}=$ 1,90). Arphia, the heavier of the two genera $(314.9 \pm 53.3 \mathrm{mg})$, had a greater but non-significant initial body water content than Trimerotropis $(269.5 \pm 38.8 \mathrm{mg})(F=23.6, \mathrm{df}=1,90)$.

\section{Metabolic rates}

The variability in metabolic rate was large; no correlation existed between rate and body size either at $22^{\circ} \mathrm{C}\left(r^{2}=0.01\right)$ or at $32^{\circ} \mathrm{C}\left(r^{2}=0.00\right)$ even when all grasshopper data were combined (Fig. 2). Similar variability was found by Menhinick (1967) with various orders of arthropods, by Cohen and Pinto (1977) for meloid beetles, and Cohen (1985) with 2 species of hemipterans. Analyses of individual regressions of metabolic rate on live weight (for each season, genus and species) indicated that in no case did the equations explain a significant amount of the variability. Because the slopes for each regression equation were not different from zero, there was no difference between any pair-wise comparison. Because of the large variability, no significant differences were observed in comparisons of mean metabolic rates between seasons, between genera or among species (Figs 3 and 4).

The $Q_{10}$ s for each season, genus, species and all grasshoppers combined were calculated for the temperature range of $22-32^{\circ} \mathrm{C}$. In most cases, metabolic rate doubled with increasing temperature. The relationship between metabolic rate and temperature 

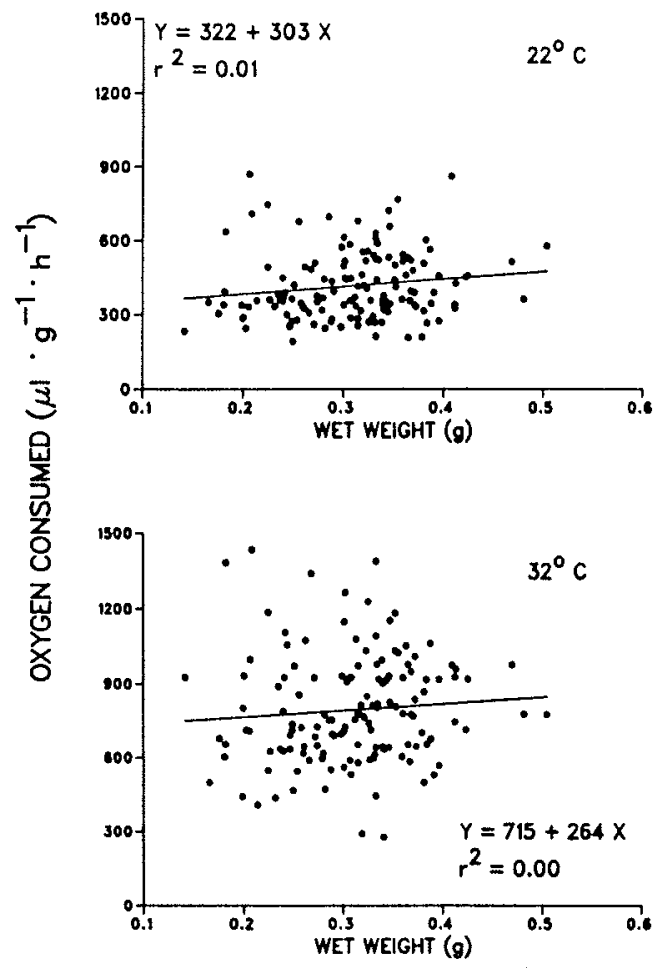

Fig. 2. The relationship between metabolic rate and live weight, for all grasshoppers (seasons, genera and species) combined, at 22 and $32^{\circ} \mathrm{C}$.

was regressed for each group and the pair-wise comparisons between slopes analysed. There were no significant differences in slopes between seasons or between genera. Among the 4 "species" comparisons, only the metabolic rate of $A$. conspersa increased significantly faster than $A$. pseudonietana $(F=4.28$, $\mathrm{df}=2,120)$. There were no differences in mean $Q_{10} \mathrm{~s}$ between each season, genus, or among species; $Q_{10} \mathrm{~s}$ ranged from $1.85 \pm 0.53$ for $A$. pseudonietana to $2.20 \pm 0.53$ for $A$. conspersa. The $Q_{10}$ for all grasshoppers combined was $2.03 \pm 0.54$.

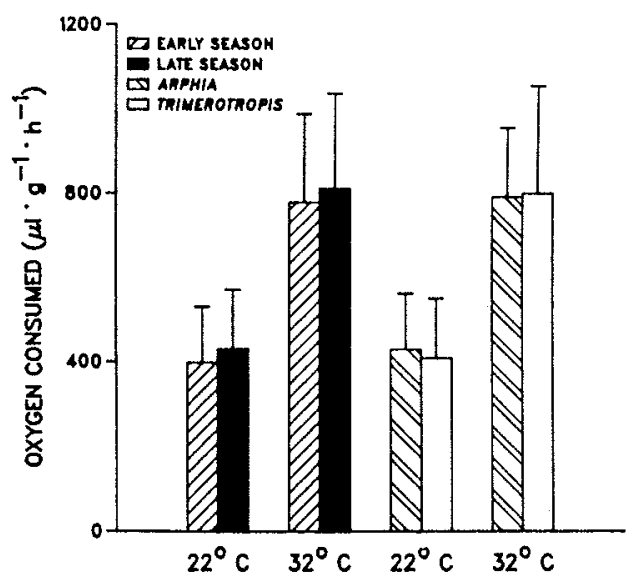

Fig. 3. Mean oxygen consumptions for seasons and genera at 22 and $32^{\circ} \mathrm{C}$. Bars represent one standard deviation above the mean.

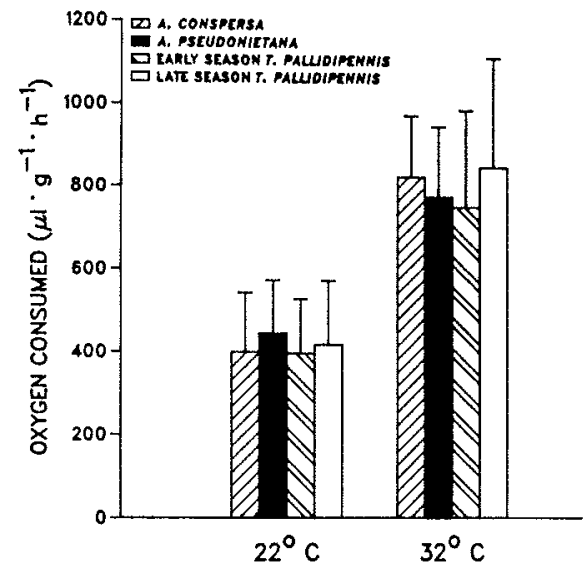

Fig. 4. Mean oxygen consumptions for the 4 "species" at 22 and $32^{\circ} \mathrm{C}$. Bars represent one standard deviation above the mean.

\section{Water loss rates}

Control trials of the desiccation experiments were designed to measure weight loss due to respiration as opposed to weight loss due to desiccation. Grasshoppers in control trials had access to water during the experiments, but after plotting the data, it became evident that only 2 of the 4 control groups located the water that was available. The weights of $A$. conspersa and late season $T$. pallidipennis fluctuated, presumably from drinking water and losing weight due to dehydration and starvation. In these 2 cases, the mean weights were greater than the original mean weight at the end of the $42 \mathrm{hr}$ run. Arphia pseudo. nietana gained weight initially (from $0 \mathrm{hr}$ to $6 \mathrm{hr}$ ) but lost weight steadily after the $9 \mathrm{hr}$ weighing. Early season $T$. pallidipennis lost water steadily from the beginning. There was no consistent variation in one direction; because of the mixed results and small sample sizes ( $n=5$ for each control group), the controls were not compared statistically to their respective experimental groups. Apparently, the experimental treatment offset any background variation present. Interpreting the results of the experimental trials may be difficult.

Percent of weight lost for those grasshoppers that failed to survive the $42 \mathrm{hr}$ trial were similar to those that survived the trial (Table 2). The insects that died may have suffered from injuries or abrasions received during capture.

An important point needs to be reiterated concerning the cumulative water loss data. The data plotted in Figs 5 and 6 are the actual mean cumulative water losses for each season, genus and species; the slopes indicate relative rates of water loss. However, since the data are cumulative, and variances inherently increase with cumulative data, assumptions relative to ANOVA were violated (i.e. variances were not constant). Therefore, the data were transformed to fit quadratic polynomial equations to equalize the variances; statistical comparisons involved comparing the slopes of the transformed data (Graybill, 1976). Slopes of quadratic polynomials are not necessarily biologically meaningful, thus slope values are not 
Table 2. Mean initial wet weight, initial body water, weight lost and weight lost per hour for seasons, genera and species of grasshoppers. Numbers followed by the same letter within the same category (wet weight, body water, etc.) are not significantly different according to LSD

\begin{tabular}{|c|c|c|c|c|}
\hline $\begin{array}{l}\text { Season, group } \\
\text { or species }\end{array}$ & $\begin{array}{c}\text { Initial } \\
\text { wet weight } \\
(\mathrm{mg} \pm \mathrm{SD})\end{array}$ & $\begin{array}{c}\text { Initial } \\
\text { body water } \\
(\% \pm \mathrm{SD})\end{array}$ & $\begin{array}{l}\text { Weight lost } \\
\text { (\% initial } \\
\text { body weight } \\
\pm \text { SD) }\end{array}$ & $\begin{array}{l}\text { Weight lost per } \\
\text { hour ( } \% \text { initial } \\
\text { body weight } \\
\pm \text { SD) }\end{array}$ \\
\hline Early season & $310.0 \pm 59.8 \mathrm{a}$ & $69.8 \pm 2.2 \mathrm{a}$ & $15.9 \pm 4.1 \mathrm{a}$ & - \\
\hline Late season & $280.3 \pm 41.3 \mathrm{~b}$ & $74.2 \pm 3.6 \mathrm{~b}$ & $14.4 \pm 4.3 \mathrm{a}$ & - \\
\hline Arphia & $314.9 \pm 53.3 \mathrm{a}$ & $73.4 \pm 3.8 \mathrm{a}$ & $13.9 \pm 4.3 \mathrm{a}$ & - \\
\hline Trimerotropis & $269.5 \pm 38.8 b$ & $71.1 \pm 3.3 \mathrm{a}$ & $16.1 \pm 3.9 \mathrm{~b}$ & - \\
\hline A. conspersa & $341.4 \pm 59.3 \mathrm{a}$ & $69.9 \pm 1.7 \mathrm{a}$ & $17.9 \pm 3.5 \mathrm{a}$ & $0.70 \pm 0.11 \mathrm{a}$ \\
\hline $\begin{array}{l}\text { A. pseudonietana } \\
\text { Early season }\end{array}$ & $296.0 \pm 36.9 b$ & $75.9 \pm 2.7 \mathrm{~b}$ & $11.7 \pm 3.1 b$ & $0.58 \pm 0.09 b$ \\
\hline $\begin{array}{l}\text { Early season } \\
T \text {. pallidipennis } \\
\text { Late season }\end{array}$ & $278.5 \pm 37.3 c$ & $69.8 \pm 2.6 \mathrm{a}$ & $14.6 \pm 4.0 \mathrm{c}$ & $0.65 \pm 0.10 \mathrm{c}$ \\
\hline T. pallidipennis & $261.9 \pm 39.2 \mathrm{c}$ & $72.2 \pm 3.4 \mathrm{c}$ & $17.4 \pm 3.5 \mathrm{a}$ & $0.72 \pm 0.10 d$ \\
\hline
\end{tabular}

given, but the $F$-test values (calculated when the slopes were compared) are given.

Early season vs late season. Early season grasshoppers had a higher mean water loss rate than late season grasshoppers (as predicted) but the difference was not significant (Fig. 7). Since mean water loss rates were larger in early season grasshoppers, these insects also exhibited a faster cumulative water loss than late season grasshoppers (Fig. 5).

Arphia vs Trimerotropis. Differences in cumulative water losses (Fig. 5) and mean water loss rates (Fig. 7) for the two genera were not significant.

Interspecific comparisons. Grasshoppers lost water at variable rates that were only partly consistent with predicted differences. Arphia conspersa, occurring in the early season, lost water significantly faster than either A. pseudonietana, found in the late season, or early season $T$. pallidipennis. Arphia pseudonietana

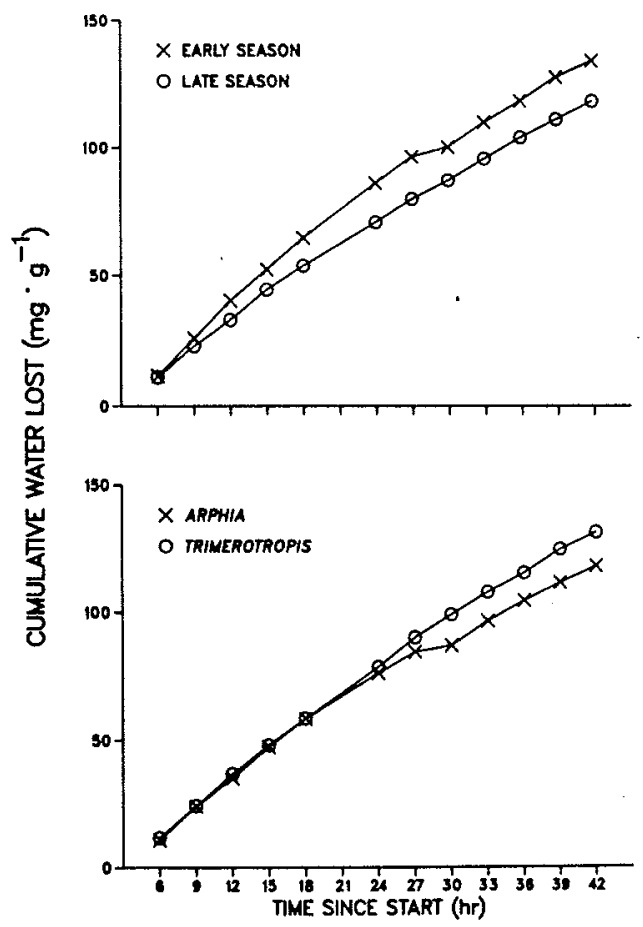

Fig. 5. Cumulative water losses for seasons and genera at $22^{\circ} \mathrm{C}$. lost water significantly slower than the other species. Differences in cumulative water losses between early and late season $T$. pallidipennis were not significant (Fig. 6).

When ANOVA was performed on mean water loss rates, significant differences were found among all 4 "species" comparisons (Fig. 7; Table 3).

To establish whether a relationship existed between body size and water loss rates in these grasshoppers, mean water loss rates per individual were plotted and regressed against body weight for all grasshoppers combined (Fig. 8). Data for all species were combined because intraspecific size differences were too small to make meaningful comparisons. There was only a weak correlation $\left(r^{2}=0.17\right)$ between mean water loss rates per individual and live weight. There was no significant correlation between water loss rates per gram and live weight $\left(r^{2}=0.00\right)$ (not shown).

In estimating surface area and surface area to volume ratios (Table 3), little relationship was found with wet weight or with rate of water loss. ANOVA and LSD tests performed on the 4 "species" indicated that all were significantly different from each other for both surface area comparisons $(F=17.74$, $\mathrm{df}=$ $3,56)$ and ratio comparisons $(F=8.57, \mathrm{df}=3,56)$.

\section{DISCUSSION}

\section{Metabolic rates}

The metabolic rate values obtained in this study are similar to values for other grasshoppers reported

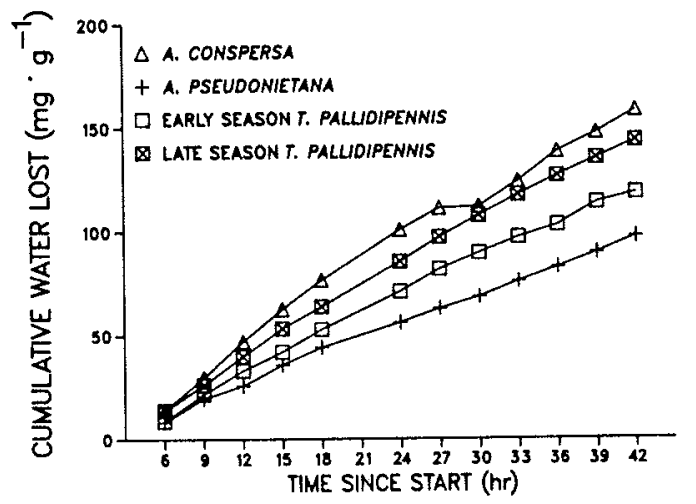

Fig. 6. Cumulative water losses for the 4 "species" at $22^{\circ} \mathrm{C}$. 

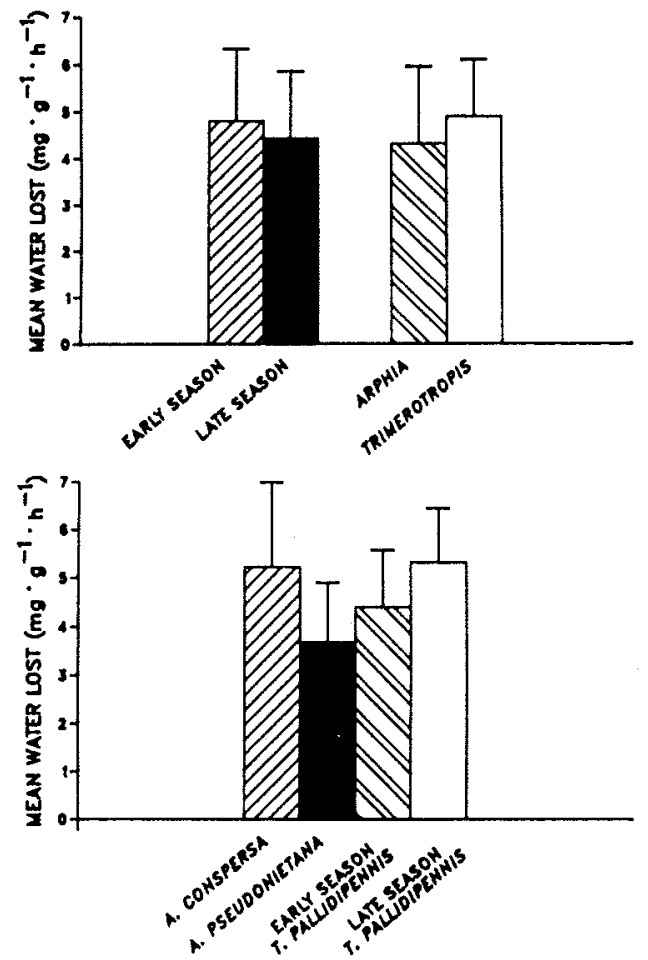

Fig. 7. Mean water loss rates for seasons, genera and species at $22^{\circ} \mathrm{C}$. Bars represent one standard deviation above the mean.

in the literature (Table 4). This is somewhat surprising given the number of factors that can influence insect metabolism.

Intraspecifically, variation in metabolic rates was large. Such high variability could have been a major cause of the lack of significant differences among species, between seasons and between genera. Based

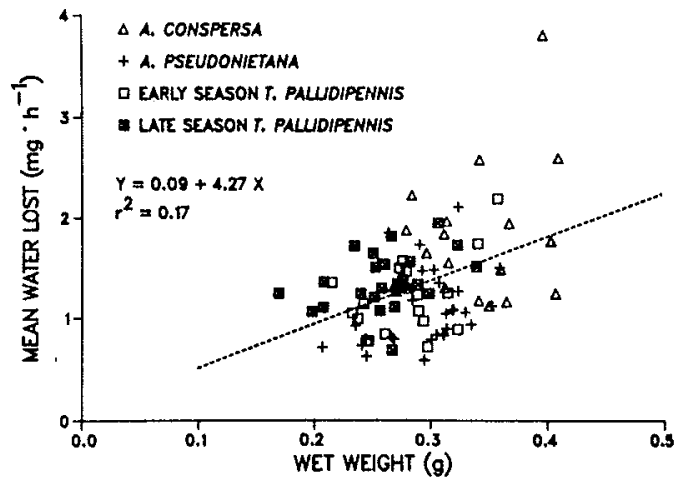

Fig. 8. The relationship between mean water loss rate and wet weight for all grasshoppers combined at $22^{\circ} \mathrm{C}$ and $<5 \%$ r.h. Mean water loss rate is presented here as water lost per individual rather than per gram as in previous figures. Although the correlation was very weak, the $r^{2}$ was 0.00 when water lost per gram was regressed against live weight.

on casual observations of the activity of these species in the field, Arphia species should have had higher oxygen consumption rates than the Trimerotropis cohorts. When flushed from the ground, Arphia generally stayed in flight for a much longer time and typically flew more than $20 \mathrm{~m}$. In contrast, the

Table 3. Estimated surface areas and surface area to volume ratios of grasshoppers studied

\begin{tabular}{|c|c|c|}
\hline Species & $\begin{array}{c}\text { Surface area } \\
\left(\mathrm{cm}^{2} \pm \mathrm{SD}\right)\end{array}$ & $\begin{array}{l}\text { Surface area to } \\
\text { volume ratio } \\
\left(\mathrm{cm}^{2} / \mathrm{cm}^{3} \pm \mathrm{SD}\right)\end{array}$ \\
\hline A. conspersa & $4.8 \pm 0.4$ & $7.9 \pm 0.5$ \\
\hline $\begin{array}{l}\text { A. pseudonietana } \\
\text { Early season }\end{array}$ & $5.4 \pm 0.5$ & $7.6 \pm 0.3$ \\
\hline $\begin{array}{l}T . \text { pallidipennis } \\
\text { Late season }\end{array}$ & $5.1 \pm 0.3$ & $8.0 \pm 0.3$ \\
\hline T. pallidipennis & $4.5 \pm 0.5$ & $8.4 \pm 0.7$ \\
\hline
\end{tabular}

Table 4. Summary of literature records of grasshopper metabolic rate

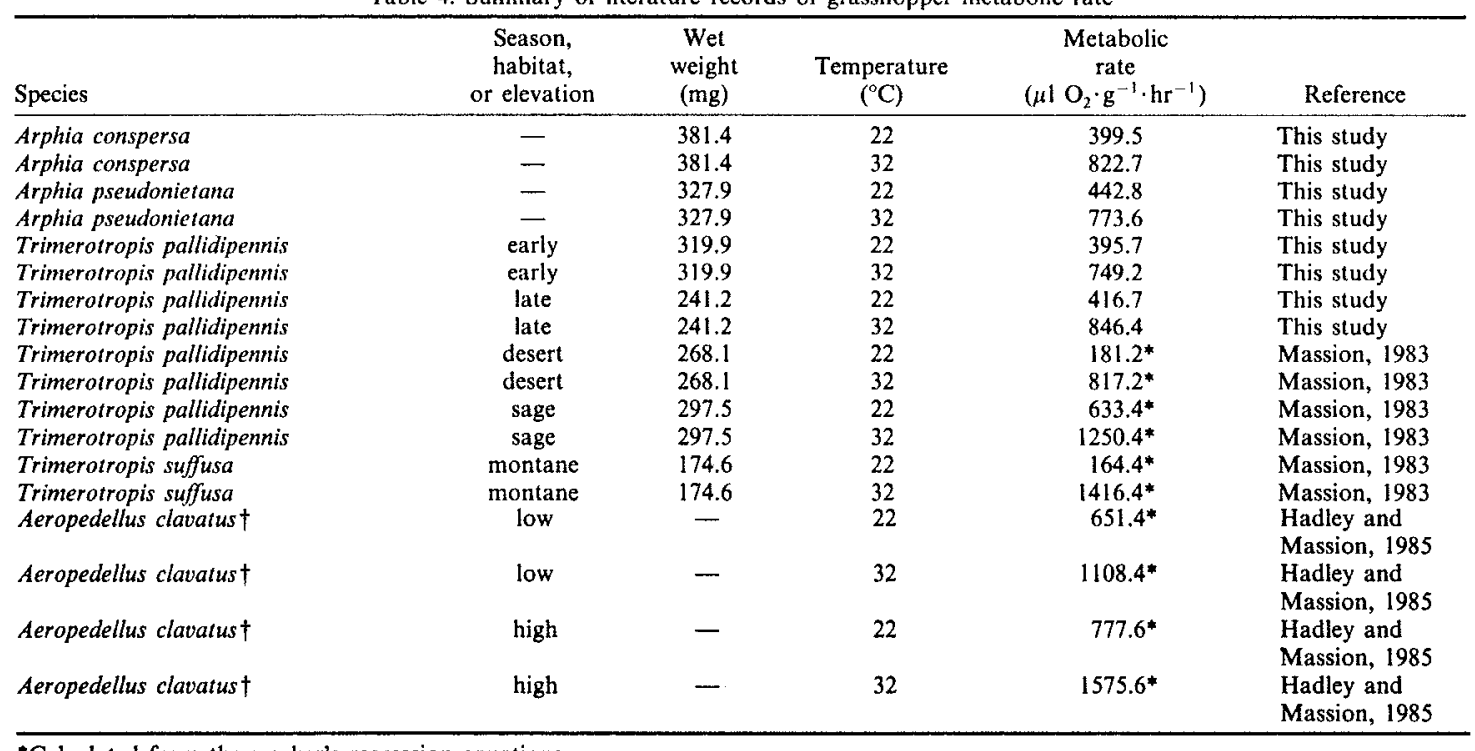

* Calculated from the worker's regression equations.

†Males and females combined. 
Table 5. Summary of literature records for grasshopper water loss rates and percent initial weight lost per hour. All studies listed here were conducted in dry air (r.h. $<5 \%$ )

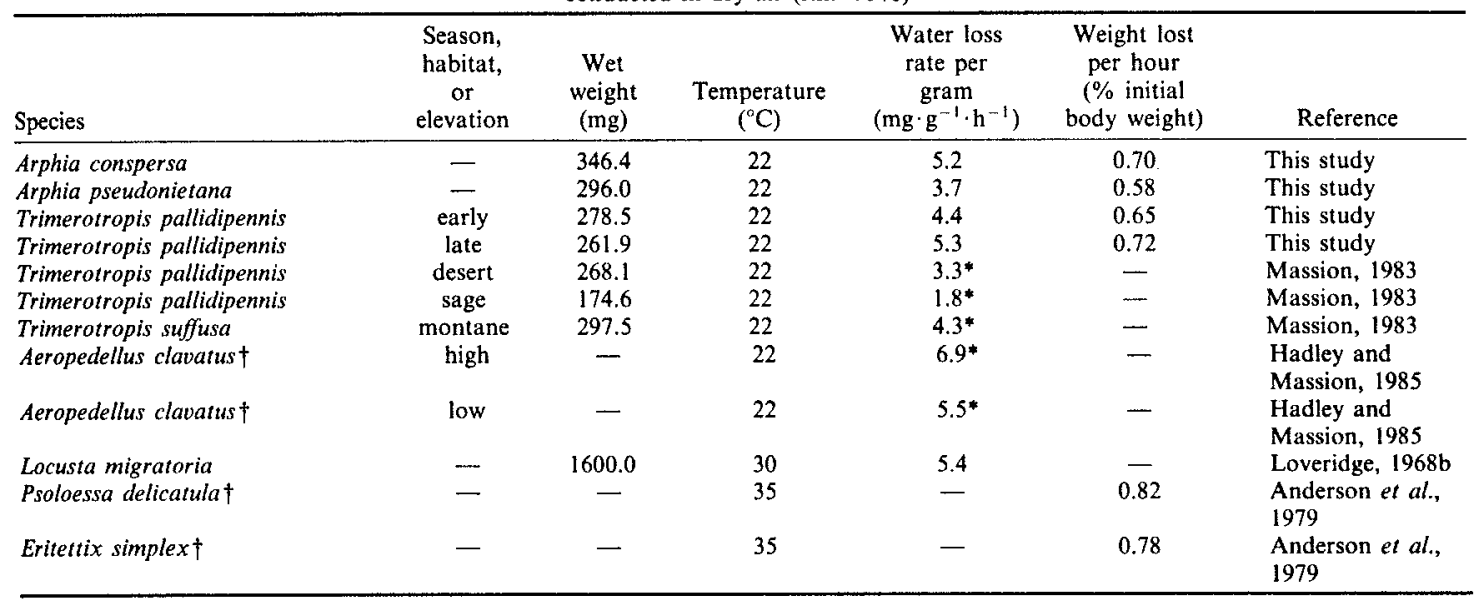

*Calculated from the worker's regression equations.

†Males and females combined.

Trimerotropis individuals had a tendency to land shortly after being flushed from the ground and typically within $3 \mathrm{~m}$ from the point of disturbance. In addition, male Arphia displayed aerially more extensively than did Trimerotropis.

In no case did metabolic rates decrease with increasing body weight. Reichle (1968) and Mispagel (1981), among others, demonstrated that large arthropods exhibit lower metabolic rates than do small ones. However in both of these studies, species used spanned several orders of magnitude of weight, ranging from 2 to $1630 \mathrm{mg}$ and 0.11 to $816 \mathrm{mg}$, respectively. In this study, most regressions showed slight positive correlations although none of the slopes differed from zero. The absence of this inverse relationship may be a result of using grasshoppers of a narrow range of weights. Loveridge and Bursell (1975), working with male Locusta, also reported a positive correlation between metabolic rate and body weight (weights ranged from 1.2 to $1.8 \mathrm{~g}$ ).

The $Q_{10}$ values reported in this study (2.03 for all grasshoppers combined) are similar to those calculated for other grasshoppers over similar temperature ranges. Mispagel (1978) recorded a $Q_{10}$ of 2.00 $\left(20-30^{\circ} \mathrm{C}\right)$ for Bootetix punctatus and Massion (1983) reported $2.14\left(25-35^{\circ} \mathrm{C}\right)$ for Trimerotropis pallidipennis. However, Duke and Crossley (1975) calculated 2.73 for Trimerotropis saxatilis over the same temperature range used in this study $\left(22-32^{\circ} \mathrm{C}\right)$.

Reported values of oxygen consumption in insects vary greatly, reflecting a combination of factors that affect the physiological state of the insect. Metabolism of adult male locusts, Schistocerca gregaria, can vary with age. Hamilton (1964) showed that within 5 days after ecdysis, metabolism increased; from 5-30 days, the rate decreased and from 35-70 days, the metabolic rate increased again. The grasshoppers in this study were captured as adults but the ages beyond ecdysis were unknown.

Gonadal condition is another factor that can alter metabolic rate in insects (Hamilton, 1964). Male facefly (Musca autumnalis) metabolism increased during spermatophoric development (Guerra and Cochran, 1970). The grasshoppers in the current study were not examined with respect to reproductive condition. However, a few individuals were observed in the field displaying to females. Thus, some of the metabolic variation observed in the data may have been due to individuals with increased rates associated with gonadal growth.

Diet and feeding histories prior to trials can influence metabolism (Clarke, 1957). Cohen (1985) found that a diet of insect eggs raised the metabolic rates in the hemipteran Geocoris punctipes two to five times greater than individuals fed lepidopteran larvae and green beans. Individuals of all 4 "species" in this investigation were fed bran, lettuce and grasses, but the effect of these foods on metabolic rate and time of each grasshopper's feeding bout were not recorded.

The thermal acclimation history of the insects prior to respiration measurements may also affect metabolic rates (Hill, 1976; Chapman, 1982). Many respiration experiments are conducted immediately after insect capture or within 2 days of capture (Cohen and Pinto, 1977; Cohen and Cohen, 1981; Massion, 1983; Hadley and Massion, 1985). Hence, it is not known whether species differences are due to acclimation history or genetic differences. In this study, differences due to environmental history were minimized by acclimating the test animals to similar conditions for 1 week. That there were no significant differences in metabolic rates suggest that the 4 "species" are genetically programmed to respond in a similar manner under similar conditions.

\section{Water loss rates}

Direct comparisons with other water balance studies are often difficult because different species, research protocol (i.e. experimental and pre-experimental procedures) and environmental conditions were used in much of the earlier experimental work. Nevertheless, the species in this study have mean 
that this species preferred temperatures below $46^{\circ} \mathrm{C}$ in the field. Gillis and Possai (1983) reported that $A$. conspersa tolerated a maximum temperature of $39.9^{\circ} \mathrm{C}$ in the field.

The total biology of insects reflects the influence of many physiological factors that may be difficult to disentangle. Since analyses of the data, with reference to season, have given mixed results, it is evident that further experimentation is necessary. Further work might include an emphasis on total survival time during desiccating conditions and the relationship of preferred temperatures with water loss by the species.

Acknowledgements-We would like to thank L. Jech and S. Durham for their assistance in the statistical analyses, S. Vander Wall and A. Finkelstein for providing helpful comments on the manuscript and $\mathrm{E}$. Zurcher for the graphics. Funding for the research was provided by the Arid Land Rehabilitation Project at Utah State University (NSF Grants DEB 81-01827 and BSR 83-17358).

\section{REFERENCES}

Abushama F. T. (1970) Loss of water from the grasshopper Poecilocerus hieroglyphicus (Klug), compared with the tree locust Anacridium melanerhodon melanerhodon (Walker). Z. angew. Ent. 66, 160-167.

Ahearn G. A. and Hadley N. F. (1969) The effects of temperature and humidity on water loss in two desert tenebrionid beetles, Eleodes armata and Cryptoglossa verrucosa. Comp. Biochem. Physiol. 30, 739-749.

Anderson R. V., Tracy C. R. and Abramsky Z. (1979) Habitat selection in two species of short horned grasshoppers: the role of thermal and hydric stress. Oecologia, Berl. 38, 359-374.

Caldwell M. M. and Fernandez O. A. (1975) Dynamics of Great Basin shrub root systems. In Environmental Physiology of Desert Organisms (Edited by Hadley N. F.), pp. 38-51. Dowden, Hutchinson and Ross, Stroudsburg.

Chapman R. F. (1982) The Insects: Structure and Function, 3rd edn. Harvard University Press, Cambridge.

Chappell M. A. (1983a) Metabolism and thermoregulation in desert and montane grasshoppers. Oecologia, Berl. 56, 126-131.

Chappell M. A. (1983b) Thermal limitations to escape responses in desert grasshoppers. Anim. Behav. 31, 1088-1093.

Clarke K. U. (1957) The relationship of oxygen consumption to age and weight during the post-embryonic growth of Locusta migratoria L. J. exp. Biol. 34, 29-41.

Cohen A. C. (1985) Metabolic rates of two hemipteran members of a predator-prey complex. Comp. Biochem. Physiol. 81A, 833-836.

Cohen A. C. and Cohen J. L. (1981) Microclimate, temperature and water relations of two species of desert cockroaches. Comp. Biochem. Physiol. 69A, 165-167.

Cohen A. C. and Pinto J. D. (1977) An evaluation of xeric adaptiveness of several species of blister beetles (Meloidae). Ann. Ent. Soc. Am. 70, 741-749.

Duke K. M. and Crossley D. A. (1975) Population energetics and ecology of the rock grasshopper, Trimerotropis saxatilis. Ecology 56, 1106-1117.

Edney E. B. (1971) Some aspects of water balance in tenebrionid beetles and a thysanuran from the Namib Desert of Southern Africa. Physiol. Zool. 44, 61-76.

Fogel M. M. (1981) Precipitation in the desert. In Water in Desert Ecosystems, Vol. 2 (Edited by Evans D. D. and Thames J. L.), pp. 219-234. Dowden, Hutchinson and Ross, Stroudsburg.
Gillis J. E. and Possai K. W. (1983) Thermal niche partitioning in the grasshoppers Arphia conspersa and Trimerotropis suffusa from a montane habitat in central Colorado. Ecol. Ent. 8, 155-161.

Graybill F. A. (1976) Theory and Application of the Linear Model. Duxbury Press, North Scituate.

Guerra A. A. and Cochran D. G. (1970) Respiration during the life cycle of the face fly. J. Econ. Ent. 63, 918-921.

Hadley N. F. and Massion D. D. (1985) Oxygen consumption, water loss and cuticular lipids of high and low elevation populations of the grasshopper Aeropedellus clavatus (Orthoptera: Acrididae). Comp. Biochem. Physiol. 80A, 307-311.

Hamilton A. G. (1964) The occurrence of periodic or continuous discharge of carbon dioxide by male desert locusts (Schistocerca gregaria Forskal) measured by an infra-red gas analyzer. Proc. R. Soc. Lond. 160B, 373-395.

Harris G. A. and Campbell G. S. (1981) Morphological and physiological characteristics of desert plants. In Water in Desert Ecosystems (Edited by Evans D. D. and Thames J. L.), Vol. 2, pp. 59-74. Dowden, Hutchinson and Ross, Stroudsburg.

Hill R. W. (1976) Comparative Physiology of Animals: an Environmental Approach. Harper and Row, New York.

Keister M. and Buck J. (1964) Respiration: some exogenous and endogenous effects on rate of respiration. In The Physiology of Insecta (Edited by Rockstein M.), pp. 617-658. Academic Press, New York.

Kemp W. P. (1986) Thermoregulation in three rangeland grasshopper species. Can. Ent. 118, 335-343.

Loveridge J. P. (1968a) The control of water loss in Locusta migratoria migratorioides $\mathrm{R} . \&$ F. I. Cuticular water loss. J. exp. Biol. 49, 1-13.

Loveridge J. P. (1968b) The control of water loss in Locusta migratoria migratorioides $\mathrm{R}$. \& F. II. Water loss through the spiracles. J. exp. Biol. 49, 15-29.

Loveridge J. P. and Bursell E. (1975) Studies on the water relations of adult locusts (Orthoptera, Acrididae). I. Respiration and the production of metabolic water. Bull. Ent. Res. 65, 13-20.

Massion D. D. (1983) An altitudinal comparison of water and metabolic relations in two acridid grasshoppers (Orthoptera). Comp. Biochem. Physiol. 74A, 101-105.

Menhinick E. F. (1967) Structure, stability and energy flow in plants and arthropods in a Sericea lespedeza stand. Ecol. Monogr. 37, 255-272.

Mispagel M. E. (1978) The ecology and bioenergetics of the acridid grasshopper, Bootettix punctatus on creosote bush, Larrea tridentata, in the northern Mojave Desert. Ecology 59, 779-788.

Mispagel M. E. (1981) Relation of oxygen consumption to size and temperature in desert arthropods. Ecol. Ent. 6, 423-431.

Patten D. T. and Smith E. M. (1975) Heat fux and the thermal regime of desert plants. In Environmental Physiology of Desert Organisms (Edited by Hadley N. F.), pp. 1-19. Dowden, Hutchinson and Ross, Stroudsburg.

Quinlan M. C. and Hadley N. F. (1982) A new system for concurrent measurement of respiration and water loss in arthropods. J. exp. Zool. 222, 255-263.

Riddle W. A. (1978) Respiratory physiology of the desert scorpion Paruroctonus utahensis. J. Arid. Environ. 1, 243-251.

Reichle D. E. (1968) Relation of body size to food intake, oxygen consumption, and trace element metabolism in forest floor arthropods. Ecology 49, 538-542.

Sala O. E., Lauenroth W. K., Parton W. J. and Trlica M. J. (1981) Water status of soil and vegetation in a shortgrass steppe. Oecologia, Berl. 48, 327-331.

Shaw J. and Stobbart R. H. (1972) The water balance and osmoregulatory physiology of the desert locust (Schistocerca gregaria) and other desert and xeric arthropods. Symp. Zool. Soc. Lond. 31, 15-38. 
Slobodchikoff C. N. (1983) Water balance and temperature preferences and their role in regulating activity of tenebrionid beetles. Oikos 40, 113-119.

Steele R. G. D. and Torrie J. H. (1980) Principles and Procedures of Statistics: A Biometrical Approach, 2nd edn. McGraw-Hill, New York.
Vollmer A. T. and MacMahon J. A. (1974) Comparative water relations of five species of spiders from different habitats. Comp. Biochem. Physiol. 47A, 753-765.

Weis-Fogh T. (1967) Respiration and tracheal ventilation in locusts and other fiying insects. J. exp. Biol. 47, 561-587. 